\title{
Orbital Trauma
}

Kirkland N. Lozada, MD ${ }^{1}$ Patrick W. Cleveland, MD² Jesse E. Smith, MD, FACS ${ }^{3}$

${ }^{1}$ Department of Otolaryngology Head \& Neck Surgery, New York Eye \& Ear Infirmary of Mount Sinai, New York, New York

2 Department of Otolaryngology Head \& Neck Surgery, The Ohio State

Address for correspondence Kirkland N. Lozada, MD, Department of Otolaryngology Head \& Neck Surgery, New York Eye \& Ear Infirmary of University Wexner Medical Center, Columbus, Ohio

3 Otolaryngology and Facial Plastic Surgery Associates, Mount Sinai, New York, New York (e-mail: Kirkland.Lozada@gmail.com).

Fort Worth, Texas

Semin Plast Surg 2019;33:106-113.

\begin{abstract}
Keywords

- orbital trauma

- fixation

- reduction

- fracture
\end{abstract}

Orbital trauma is a frequent cause of damage to both bony, soft tissue and neurovascular structures in the surrounding region. Injury patterns can be isolated to the bony orbit or part of much larger zygomaticomaxillary complex (ZMC), or panfacial fracture patterns. This critical area brings together many specialties including otolaryngology, plastic surgery, oral maxillofacial surgery, ophthalmology, neurosurgery, and emergency medicine. The aim of this review is to summarize orbital reconstruction in the following frac- ture patterns: orbital wall, ZMC, and naso-orbito-ethmoid (NOE).

\section{Orbital Anatomy}

The orbital floor is made up by the maxillary, zygomatic, and palatine bones ( - Fig. 1). It makes up the roof of the maxillary sinus and is in close relation to the inferior rectus muscle. The infraorbital nerve (branch of V2) exits its foramen in the

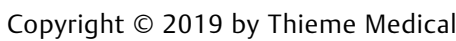
Publishers, Inc., 333 Seventh Avenue, New York, NY 10001, USA. Tel: +1(212) 584-4662. ISSN 1535-2188. 


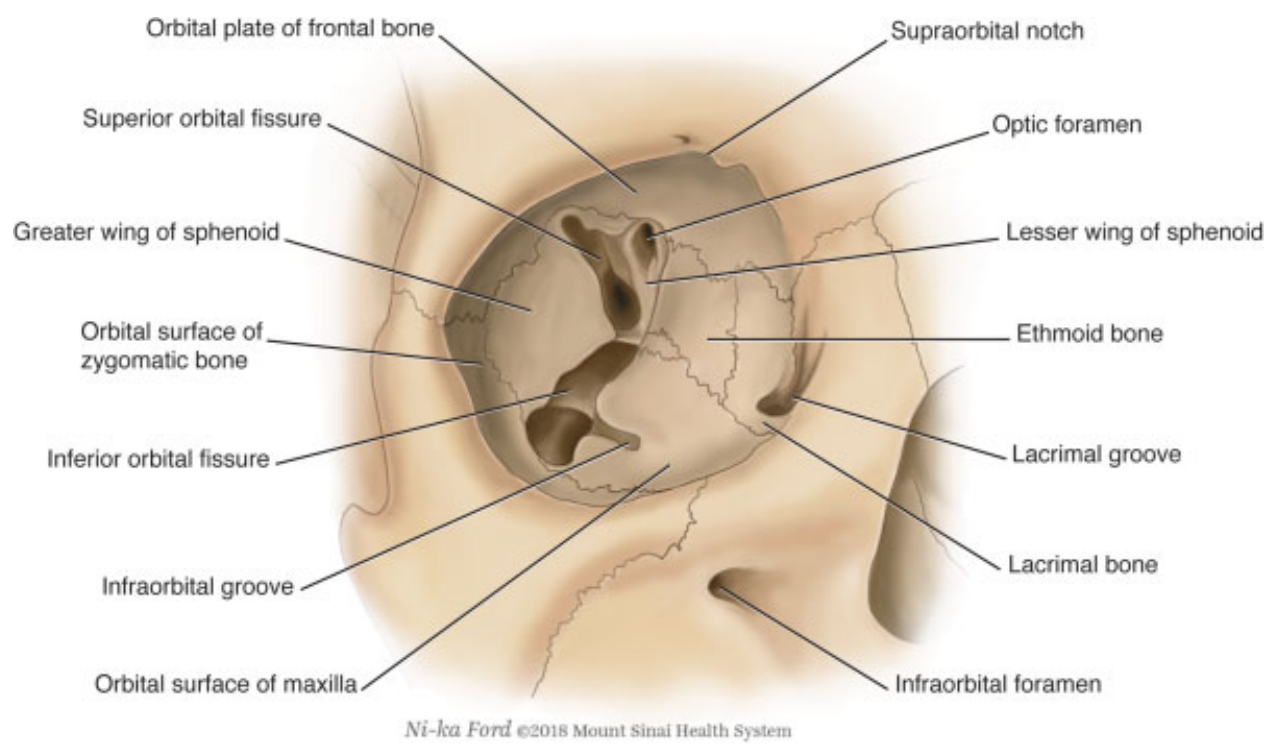

Fig. 1 Bony anatomy of the orbit.

maxilla providing sensation to the floor and tissue overlying the midface.

The medial orbital wall is made up by the frontal process of maxilla, lacrimal bone, ethmoid, and sphenoid bone. The lamina papyracea is a thin bone separating the orbital cavity from the ethmoid sinuses and is frequently damaged in trauma. The medial rectus muscle is closely related to the medial orbital wall and can be entrapped when damaged. The anterior and posterior ethmoid arteries are found at the junction of the medial orbital wall and orbital roof. Other important structures include the lacrimal sac, medial canthal tendon (MCT), and trochlea. ${ }^{1}$

The zygomatic bone is located in an important position in the midface providing appropriate midface width, cheek definition, and shape/definition to the lateral and inferior orbital borders. ${ }^{2} \mathrm{ZMC}$ fractures are frequently seen in clinical practice. Fractures frequently involve the orbital rim and orbital floor. Important anatomic consequences of ZMC fractures include hypophthalmos, enophthalmos, midfacial widening, and loss of malar projection. ${ }^{3}$

Understanding the anatomy involved in orbital trauma is important in diagnosing and repairing the underlying pathology. Thus, computed tomography (CT) scanning is an essential part of working up facial trauma especially since sequelae of facial trauma can also be intracranial injury. Somasundaram et al found in a 3-year series that periorbital ecchymosis accompanied skull base fractures and intracranial hemorrhage 42 and $19 \%$ of the time, respectively. Furthermore, in patients with orbital fractures who do not have suspected traumatic brain injury, Lee et al discovered intracranial trauma present $9 \%$ of the time in the largest series to date. A statistically significant correlation with intracranial trauma was found with superior orbit fractures, frontal sinus fractures, and multiple facial fractures. Until prospective data are available these features along with advanced age should be used to help guide when intracranial CT scanning is indicated. ${ }^{4-8}$

\section{Zygomaticomaxillary Orbital Rim Fractures}

Orbital rim fractures are traditionally seen as part of a larger fracture pattern, i.e., ZMC, orbital wall fractures, and Le Fort fractures. The orbital rim, as mentioned previously, is important for providing normal contours of the orbital border. The orbital rim is made up of the zygomatic bone and its connections to the maxillary and frontal bones at the zygomaticomaxillary and zygomaticofrontal buttresses, respectively. On physical examination orbital rim fractures can create palpable "step-offs" that can be freely palpated. This can be useful to the surgeon intraoperatively to ensure that adequate reduction of the fracture has been achieved when the step-off is no longer palpable. Trigeminal nerve branch (V2) function should be tested preoperatively and documented appropriately.

Approaches to the orbital rim are similar to those used for all midface fractures. The lower orbital rim can be directly exposed via transconjunctival, orbital rim, subtarsal, subciliary incisions, or through an existing laceration. In ZMC or Le Fort fracture patterns, a maxillary vestibular incision may be combined with a transconjunctival or subciliary incision to provide wide exposure of the entire inferior orbital rim and midface. The upper orbital rim can be exposed via an upper blepharoplasty incision and/or lateral brow incision. For wider exposure a coronal or bicoronal incision may be needed.

Extensive exposure of midface fractures for routine plating of all four buttresses was found to give patients a lifeless facial appearance; thus, a shift towards a more "minimally invasive" approach to midface fractures developed. ${ }^{3}$ This has also reduced the complications from repair of ZMC, Le Fort, and orbital fractures. Important complications include malunion, ectropion, entropion, scleral show, lid shortening, and midface ptosis.

Not every orbital rim fracture, or midface fracture, requires operative intervention. If the fracture is minimally displaced or nondisplaced, with no resulting cosmetic deformity, it is possible to avoid surgery. However, for fractures that are displaced with palpable step-offs, cosmetic deformity, 
resulting enophthalmos, or hypophthalmos, open reduction internal fixation is the preferred method of treatment. The repair of orbital rim fractures follows the principles of all facial fractures with atraumatic technique, anatomic reduction of fragments, and a stable fixation. These were defined by the AO Foundation (Arbeitsgemeinschaft für Osteosynthesefragen, Davos, Switzerland). ${ }^{9}$ Reconstruction using orbital rim miniplates with placement of 2 to 4 screws on either side of the fracture line will ensure adequate stabilization. It should be noted that the skin overlying the inferior orbital rim and the zygomaticofrontal suture line is quite thin, and the use of lowprofile miniplates will aid in reducing palpable hardware by the patient postoperatively.

\section{Orbital Floor Fractures}

The orbital floor acts as a cradle for the orbital contents and as a result fractures place the adjacent fat, muscle, and globe at risk. The orbit is an enclosed space and is shaped like a pyramid lying on its side. ${ }^{10}$ There are two theories as to how orbital floor fractures occur. The first is that hydraulic forces transferred through the enclosed orbital contents exert themselves on the weakest area of bone, often blowing out the orbital floor, first described by Pfeiffer. ${ }^{11}$ Although the lamina papyracea is thinner than the floor, the adjacent honeycombing of the ethmoid partitions helps to buttress it against a sudden rise in intraorbital pressure better than the unbuttressed orbital floor; therefore, there is a higher incidence of floor fractures than medial orbital wall fractures. The second theory, described by Le Fort, is that forces exerted on the orbital rim lead to buckling of the orbital floor causing a fracture to ensue at its weakest points. ${ }^{12}$

Various forces can lead to different fracture patterns, each with their own considerations. Some floor fractures can be continuous with the orbital rim or ZMC fractures. A direct blow can cause a fracture in the orbital rim and then continued rotation of that bony segment around a pivot point causes a secondary fracture at the pivot point (orbital floor). In addition to the cosmetic issues discussed above with rim and ZMC fractures, orbital volume restoration must be considered as this fracture pattern always involves some component of the orbital floor. The most common type of fracture is the "blow out" fracture. In "blow out fractures", the rim remains intact with no resulting cosmetic change; however, lack of support from the lax inferior segment results in volume loss which can result in hypophthalmos and diplopia. The fractured edges may also snag orbital contents, such as the inferior rectus, resulting in ocular entrapment. Another type of floor fracture is the trap door fracture, which appears as a linear, minimally displaced fracture, and occurs primarily in youthful patients. The foremost consideration in these fractures is entrapment of the inferior rectus muscle. The initial traumatic force causes a linear fracture and displacement of the floor and orbital content downward. After the traumatic force ceases the bony floor segment recoils quicker than the displaced orbital contents which traps them. These fractures are most commonly experienced when bone is highly elastic, which is why they almost exclusively occur in children and young adults. ${ }^{13}$
Due to the minimal displacement of these fractures, orbital volume loss is rarely of concern. ${ }^{14-17}$

The force associated with orbital floor fractures is significant and can lead to other ocular and orbital complications. The reported rate of ocular complications varies from 2.7 to $90.6 \%$ in the literature depending on inclusion criteria with severe ocular complications occurring in 10 to $13.7 \%$ of orbital fractures. ${ }^{18-21}$ Ophthalmologic evaluation of the globe is paramount in the initial evaluation, as the trauma and transmitted hydraulic forces through the globe can lead to corneal abrasion, hyphema, traumatic iritis, lens subluxation, capsule rupture, vitreous hemorrhage, retinal detachment, and globe rupture. When the globe appears proptotic and tense, intraocular pressures should be obtained, and an orbital hematoma should be suspected. Orbital hematomas can lead to orbital compartment syndrome, and emergent lateral canthotomy and cantholysis may be necessary to prevent ischemic damage. ${ }^{22,23}$

Operative management of orbital floor fractures depends on several considerations. The most immediate concern is whether or not there is entrapment of the medial or inferior rectus muscle. Entrapment can lead to compromise of the muscle's vascular supply, resulting in necrosis, fibrosis, and scarring. Entrapment can be difficult to assess when the orbital soft tissues are acutely swollen and is best evaluated with forced duction testing. In extreme cases patients with entrapment can experience bradycardia, nausea, and syncope when attempting extraocular movements (the oculocardiac reflex), and immediate operative reduction with release of the entrapped muscle is of immediate importance. ${ }^{15-17,24-26}$ The most common indication for repair is correction of enophthalmos, resulting from the loss of support of the orbital floor. A small amount of hypophthalmos can be tolerated both cosmetically and functionally; however, the degree of floor loss that does require repair is often debated. As a general rule $>2 \mathrm{~mm}$ of hypophthalmos, or $>50 \%$ involvement of the orbital floor, will necessitate repair to prevent diplopia and obvious ocular asymmetry. Some data suggest comparable outcomes with late repairs; however, delayed repairs are technically more difficult. ${ }^{27-29}$

The approach to the orbital floor can be accomplished through several different incisions, and unlike other parts of the face, lacerations may not provide adequate access. The most common and cosmetically acceptable is the transconjunctival approach. This not only avoids a skin incision but can be extended laterally via lateral canthotomy, and medially via a transcaruncular incision when access to adjacent structures is required. Subciliary incisions and mid-eyelid incisions can also be performed, but isolated orbital floor fractures can usually be completely exposed with the transconjunctival approach alone. All incisions carry the risk of entropion or ectropion based on their position with respect to lid margin, but some studies show that the risk is minimized with the transconjunctival approach. ${ }^{30-35}$

During orbital floor repairs, careful attention must be given to excellent visualization and the placement of the implant (-Fig. 2). Failure to place the implant on the posterior ledge (greater wing of the sphenoid) can result in 


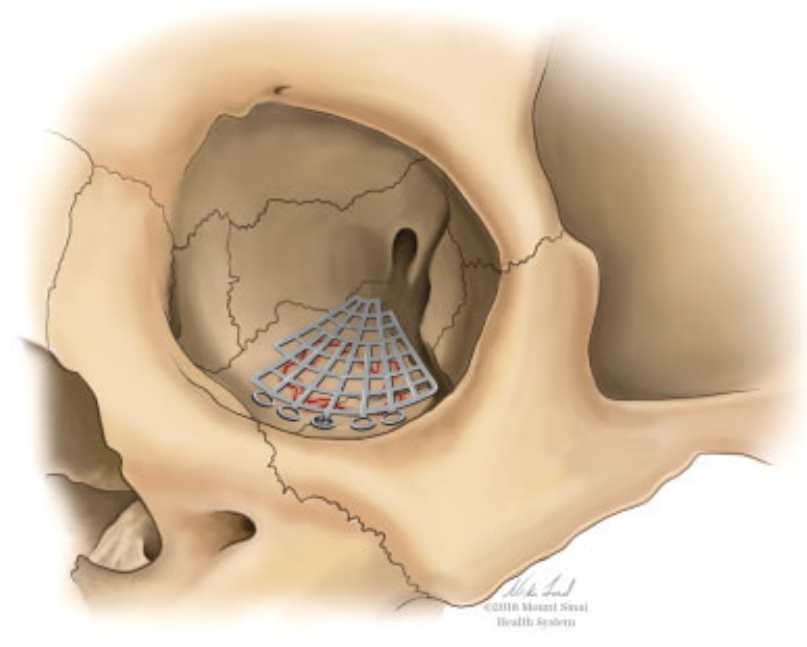

Fig. 2 Reconstruction demonstrated with titanium mesh for an isolated orbital floor fracture.

inadequate volume restoration from gross malposition of the implant and periorbital soft tissues in the maxillary sinus. Beyond confirming placement with palpation and visualization, recent studies show that intraoperative CT scanning and surgical navigation can be helpful tools for verifying ideal implant placement. ${ }^{36,37}$ Reduction of orbital contents superior to the repair is of paramount importance, so that the implant or graft does not entrap the infraorbital nerve or rectus and oblique muscles. With complete reduction the orbital volume can be restored, and long-term diplopia can be avoided. ${ }^{16,27,35}$

\section{Medial Orbital Wall Fracture}

Orbit wall fractures often occur in conjunction with orbital floor fractures, though they can occur in isolation. The incidence of isolated medial wall fractures varies widely in the literature from 0 to $55 \% .^{38}$ These fractures can be clinically occult, which likely explains the variability in reporting. Indications for surgery are similar to floor fractures and repair is indicated when there is entrapment or $>2 \mathrm{~mm}$ of hypophthalmos present; however, predicting who will develop late hypophthalmos or enophthalmos is decidedly more difficult than with floor fractures.

Surgical repair is ideally accomplished through a transcaruncular incision given its favorable access and aesthetics, though endoscopic techniques and a lynch incision approach have been used as well. During the transcaruncular approach, the inferior oblique muscle is at risk of injury in the initial dissection, and its location between the orbital rim and bony lacrimal canal must be avoided. The adjacent neurovascular anatomy must also be considered during dissection as the anterior ethmoid artery, posterior ethmoid artery, and optic canal are at risk of injury and located approximately 24,36 , and $42 \mathrm{~mm}$ posterior to the lacrimal crest, respectively. Again, plate placement over the stable, posterior ledge is important to restore orbital volume. For large defects extending onto the floor, preformed, contoured orbital plates can be useful in order to restore proper orbital volume. $^{38-40}$

\section{Orbital Roof Fracture}

Orbital roof fractures are rare and estimated to make up only 1 to $9 \%$ of all orbit fractures. They are usually related to adjacent trauma to the orbital rim but can occur from hydraulic forces within the cranial vault resulting in a "blow-in" fracture. "Blow-in" fractures are associated with intracranial injury such as countercoup injuries, frontal contusions, and frontal hemorrhage and are most commonly caused by occipital trauma. ${ }^{41-43}$ In the absence of diplopia, globe malposition, cerebrospinal fluid (CSF) leak, or rectus impingement, surgical intervention is not necessary. In the case of CSF oculorrhea or rhinorrhea, diagnosis is best made with testing at least $0.5 \mathrm{~mL}$ of fluid for beta- 2 transferrin given its remarkable $97 \%$ specificity and 99\% sensitivity, and the unreliability of the halo test. ${ }^{44}$ Conservative management is sometimes favored as the orbital contents work to tamponade the leak. Observation with or without lumbar drainage is recommended for the first 48 hours as it is believed to resolve up to 95\% of cranio-orbital fistulas, minimizing the need for craniotomy. ${ }^{45-47}$ Care should be taken to avoid nasal blowing, as air can present through the defect through a ball valve mechanism and compress the intracranial contents.

\section{Implants}

There are several materials that are suitable for orbital implants ranging from autogenous grafting to alloplastic implants. Some of the most commonly used implants include bone, cartilage, Medpor (Stryker), titanium, poly(L-lactide) (PLLA), and polydioxanone (PDS). ${ }^{48}$ Titanium has the advantage of being thin, malleable, and widely available, while providing excellent support. When repairing large defects titanium and other alloplastic plates can be preformed to match the contours of the medial orbital wall and orbital floor, thus spanning the entire defect. Some titanium implants come readily preformed, thus avoiding volume defects associated with poor bending techniques. Titanium also displays excellent osteointegration making it a very suitable metal for repairing bony defects. The down side is it also produces an intense fibrotic reaction that can cause adhesion to the adjacent rectus muscle and lead to late-onset diplopia, a phenomenon termed orbital adherence syndrome. ${ }^{49,50}$

In an attempt to avoid this, some surgeons use Medpor, Medpor with integrated titanium, nylon foil, PLLA plates, PDS, and silicon. However, these still share the risk of infection and extrusion shared by foreign materials. Others have described using allogenic materials, but these can have variable levels of absorption as well as the rare but serious risks of infection and rejection. Various autologous grafts have been used as well; however, they add to operative time, can be associated with additional donor site morbidity, and have unpredictable resorption. ${ }^{49-55}$

\section{Naso-Orbito-Ethmoid Fractures}

The NOE complex is a complicated bony complex that includes contributions from the maxillary, nasal, frontal, ethmoid, sphenoid, and lacrimal bones. The boundaries of 
the NOE complex are as follows: superiorly the cribriform plate, laterally the medial orbital wall, inferiorly the nasal cavity, posteriorly the sphenoid sinuses. ${ }^{56}$ The NOE complex receives sensory innervation via the ophthalmic and maxillary nerves, branches of the trigeminal nerve. Blood supply is via the internal and external carotid arteries.

Two critical anatomic structures must be reviewed when discussing NOE fractures: the MCT and the central fragment. The MCT attaches anteriorly to the frontal process of the maxilla of the lacrimal groove, posteriorly it attaches to the lacrimal bone. Laterally it attaches to the tarsus of the upper and lower eyelids. The MCT is critical for maintaining the shape and position of the palpebral fissures. The central fragment is the location of the MCT tendon on the medial vertical buttress securing the globe, eyelid, and orbicularis muscle, and is used for classification of NOE fractures. ${ }^{57}$ The nasolacrimal duct (NLD) is the apparatus where tears drain from the eye into the nasal cavity just below the inferior turbinate. The NLD is at risk of injury in NOE fractures and must be evaluated for patency.

Signs and symptoms of NOE fractures are wide ranging given the extensive nature of the injuries. Patients may complain of nasal congestion, anosmia, diplopia, telecanthus, epiphora, and CSF leak. Anosmia may result from shearing of the olfactory nerve at the cribriform plate. Telecanthus is defined as an intercanthal distance greater than $35 \mathrm{~mm}$ and occurs with disruption of the MCT. This disruption may change the shape and position of the palpebral fissures as well. Epiphora can occur when there is damage to the NLD. In rare cases CSF leak may occur secondary to damage of the cribriform plate and is heralded by CSF rhinorrhea. ${ }^{58}$

Given its central location, it is not surprising that multiple approaches to the NOE complex have been described and employed. The coronal approach is commonly used, and it provides good access to the fracture site. In order to achieve excellent exposure, the supraorbital nerves may need to be released from their bony housing near the superior orbital rims. In addition, other approaches such as gingivobuccal, subciliary, transconjunctival, and lateral rim may be used or added for exposure. It is important to utilize lacerations over the area of the NOE fracture when they are available, as these can greatly increase exposure with minimal retraction. Midfacial degloving also allows for fracture exposure; however, it should be reserved for cases where other methods of exposure have failed. The extensive dissection and elevation of important midfacial structures and the skin-soft tissue envelope should not be performed if it can be avoided. ${ }^{56,59-61}$

Fracture patterns can be described using the Markowitz classification (- Table 1). This classification scheme defines NOE fractures on the basis of the MCT attachment to the central fragment. ${ }^{57}$ Type 1 involves an intact MCT and central fragment. Type 2 has mild comminution of central fragment without MCT disruption (-Fig. 3). Type 3 includes severe comminution of central fragment and gross disruption of MCT. ${ }^{62}$ Historically, NOE fractures were treated with external plates and splints which then progressed to open reduction and internal fixation with interosseous wiring in the
Table 1 Markowitz and Mason classification system of NOE fractures

\begin{tabular}{|l|l|l|}
\hline & Medial canthal tendon & Fractured segment \\
\hline Type 1 & Attached & Single large fragment \\
\hline Type 2 & Attached & Comminuted \\
\hline Type 3 & Avulsed & Comminuted \\
\hline
\end{tabular}

Abbreviation: NOE, naso-orbito-ethmoid.

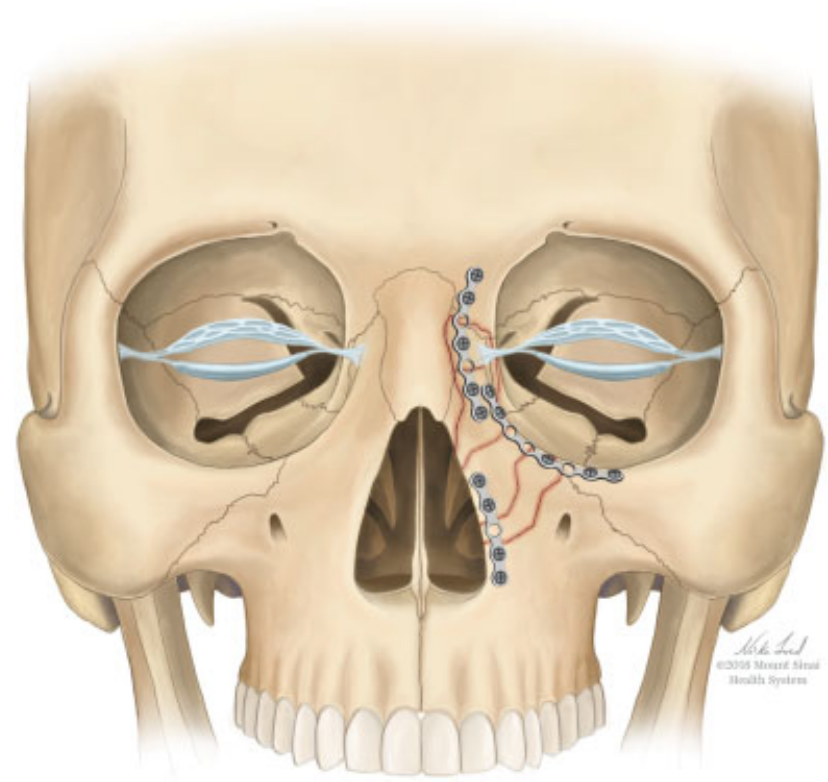

Fig. 3 Type II NOE fracture with comminuted segments involving the medial canthal tendon. Open reduction, internal fixation demonstrates reduction of the central fragment in its anatomic location to reestablish the appropriate intercanthal distance. NOE, naso-orbitoethmoid.

1960s, with improved results. Currently, open reduction internal fixation with titanium plates and screws is the technique of choice for displaced NOE fractures. ${ }^{63}$ Successful treatment of NOE fractures hinges on successful reconstruction of the MCT, restoration of central nasal and dorsal support, and reduction of the medial orbital walls.

Current plating techniques aim at restoring the bony contour by reducing the comminuted bony fragments by stabilizing them to surrounding stable bone. ${ }^{64}$ Plating should start wherever the best exposure and access is afforded. If access is uniform then aesthetics should be prioritized, starting with the frontal bone, then orbital rim, the nasal dorsum, followed by the pyriform aperture. Type 2 and 3 fractures frequently cause disruption of the central nasal support. Re-establishing support through reducing and fixating the septum to the rhinion via sutures, splints, or K-wire have all been described. If complete comminution of the nasal bones and septum occurs, primary grafting and reconstruction of nasal dorsum with a cantilevered bone graft or rib graft is indicated, and is best done at the initial operation prior to soft tissue contracture. Split calvarial grafts, rib grafts, and costochondral grafts are all potential options 
for grafting material. The graft must be secured to surrounding structures (usually the stable frontal complex) to provide a central area of support for NOE fracture repair. ${ }^{58}$

Type 1 injuries without displacement of fracture segments may be treated conservatively with outpatient follow-up and clinical monitoring. Conversely transnasal wire canthopexy is usually required in type 2 and 3 NOE fractures for optimal MCT reduction. ${ }^{65}$ Care must be taken to not only restore the posterior and medial positioning of the medial canthus, but also to not alter its vertical height. Slight overcorrection is needed with the end goal of restoring the intracanthal distance to the premorbid state $(33-34 \mathrm{~mm}$ in white males, $32-33 \mathrm{~mm}$ in females). To accomplish this, a plate is positioned so that the wire's force vector is correctly imparted on the medial canthus. Barbed canthal wires or traditional titanium wires can be used; however, atraumatic placement in the MCT is essential. ${ }^{66} \mathrm{~A}$ small vertical incision made medial to the medial canthus can be used if needed for access. After passing the wire through the MCT and plate, it traverses the nasal cavity. This is done by drilling two to four holes in the medial orbital wall and using 28-gauge wires through the holes to secure the fragments. ${ }^{56}$ When the medial orbital wall requires reconstruction the medial wall plate can be utilized for securing the canthal wire. Other options exist for MCT reconstruction such as Mitek minibone anchors. This bone anchor has a prethreaded suture which can be placed through the anterior and posterior portions of the MCT and tied down anchoring the MCT to the bone. The suture can also be placed through the overlying soft tissues adding another level of closure. ${ }^{67}$ Splints and bolsters may be employed to help in cases of severe comminution; however, care must be taken as postoperative swelling can result in skin necrosis when they are placed too tight, and a surgeon should never bypass transnasal MCT wiring in favor of splints and bolsters alone.

Nasolacrimal duct stenting has been a subject of much controversy in NOE fracture management. Studies have documented epiphora rates after NOE repair between 5 and $20 \%$ with early reduction and fixation of fractures as the best prevention against this complication. Conservative management is acceptable, with delayed dacryocystorhinostomy (DCR) and NLD stenting for several months; this method is successful in more than $90 \%$ of cases. ${ }^{68,69}$

\section{Conclusion}

Orbital trauma encompasses a wide variety of mechanisms of injury and resulting fracture patterns. A variety of surgical approaches to the orbit exist as has been discussed allowing the surgeon access to all area of interest. Regardless of the fracture complexity, the principles of atraumatic technique, anatomic reduction, and stable fixation apply in all cases.

Note

This manuscript, or any part of it, has not been previously published, nor is it under consideration for publication elsewhere.

\section{Conflicts of Interest}

The authors do not have any conflict of interest, financial or otherwise.

\section{References}

1 Joseph JM, Glavas IP. Orbital fractures: a review. Clin Ophthalmol 2011;5:95-100

2 Marinho RO, Freire-Maia B. Management of fractures of the zygomaticomaxillary complex. Oral Maxillofac Surg Clin North Am 2013;25(04):617-636

3 Ellis E III, Perez D. An algorithm for the treatment of isolated zygomatico-orbital fractures. J Oral Maxillofac Surg 2014;72(10): 1975-1983

4 Somasundaram A, Laxton AW, Perrin RG. The clinical features of periorbital ecchymosis in a series of trauma patients. Injury 2014; 45(01):203-205

5 Lee HJ, Kim YJ, Seo DW, et al. Incidence of intracranial injury in orbital wall fracture patients not classified as traumatic brain injury. Injury 2018;49(05):963-968

6 Kraus JF, Rice TM, Peek-Asa C, McArthur DL. Facial trauma and the risk of intracranial injury in motorcycle riders. Ann Emerg Med 2003;41(01):18-26

7 Haug RH, Adams JM, Conforti PJ, Likavec MJ. Cranial fractures associated with facial fractures: a review of mechanism, type, and severity of injury. J Oral Maxillofac Surg 1994;52(07): 729-733

8 Alvi A, Doherty T, Lewen G. Facial fractures and concomitant injuries in trauma patients. Laryngoscope 2003;113(01):102-106

9 Mast G, Ehrenfeld M, Cornelius CP, Tasman AJ, Litschel R. Maxillofacial fractures: midface and internal orbit-part II: principles and surgical treatment. Facial Plast Surg 2015;31(04): 357-367

10 Ghavami A, Pessa JE, Janis J, Khosla R, Reece EM, Rohrich RJ. The orbicularis retaining ligament of the medial orbit: closing the circle. Plast Reconstr Surg 2008;121(03):994-1001

11 Pfeiffer RL. Traumatic enophthalmos. Trans Am Ophthalmol Soc 1943;41:293-306

12 Tessier P. The classic reprint. Experimental study of fractures of the upper jaw. I and II. René Le Fort, M.D. Plast Reconstr Surg 1972;50:497-506

13 O-Lee TJ, Koltai PJ. Pediatric facial fractures. In: Mitchell RB, Pereira KD. eds. Pediatric Otolaryngology for the Clinician. Totowa, NJ: Humana Press; 2009:91-95

14 Phan LT, Jordan Piluek W, McCulley TJ. Orbital trapdoor fractures. Saudi J Ophthalmol 2012;26(03):277-282

15 Yano H, Suzuki Y, Yoshimoto H, Mimasu R, Hirano A. Linear-type orbital floor fracture with or without muscle involvement. J Craniofac Surg 2010;21(04):1072-1078

16 Lelli GJ Jr, Milite J, Maher E. Orbital floor fractures: evaluation, indications, approach, and pearls from an ophthalmologist's perspective. Facial Plast Surg 2007;23(03):190-9

17 Wachler BS, Holds JB. The missing muscle syndrome in blowout fractures: an indication for urgent surgery. Ophthal Plast Reconstr Surg 1998;14(01):17-18

18 Ross M, El-Haddad C, Deschênes J. Ocular injury in orbital fractures at a level I trauma center. Can J Ophthalmol 2017;52 (05):499-502

19 al-Qurainy IA, Stassen LF, Dutton GN, Moos KF, el-Attar A. The characteristics of midfacial fractures and the association with ocular injury: a prospective study. Br J Oral Maxillofac Surg 1991; 29(05):291-301

20 HoTQ Jupiter D, Tsai JH, Czerwinski M. The incidence of ocular injuries in isolated orbital fractures. Ann Plast Surg 2017;78(01):59-61

21 Luce EA, Tubb TD, Moore AM. Review of 1,000 major facial fractures and associated injuries. Plast Reconstr Surg 1979;63 (01):26-30 
22 al-Qurainy IA, Stassen LF, Dutton GN, Moos KF, el-Attar A. The characteristics of midfacial fractures and the association with ocular injury: a prospective study. Br J Oral Maxillofac Surg 1991; 29(05):291-301

23 al-Qurainy IA, Titterington DM, Dutton GN, Stassen LF, Moos KF, el-Attar A. Midfacial fractures and the eye: the development of a system for detecting patients at risk of eye injury. Br J Oral Maxillofac Surg 1991;29(06):363-367

24 Sugamata A, Yoshizawa N, Shimanaka K. Timing of operation for blowout fractures with extraocular muscle entrapment. J Plast Surg Hand Surg 2013;47(06):454-457

25 Reddy SS, Landry JP, Douglass K, Venugopalan PP. A case of ocular cardiac reflex in a child with blunt ocular trauma. BMJ Case Rep 2014;2014:bcr2014206246

26 Merali FI, Grant MP, Mahoney NR. Orbital floor fracture with atypical extraocular muscle entrapment pattern and intraoperative asystole in an adult. Craniomaxillofac Trauma Reconstr 2015; 8(04):370-374

27 Burnstine MA. Clinical recommendations for repair of isolated orbital floor fractures: an evidence-based analysis. Ophthalmology 2002;109(07):1207-1210, discussion 1210-1211, quiz $1212-1213$

28 Hawes MJ, Dortzbach RK. Surgery on orbital floor fractures. Influence of time of repair and fracture size. Ophthalmology 1983;90(09):1066-1070

29 Damgaard OE, Larsen CG, Felding UA, Toft PB, von Buchwald C. Surgical timing of the orbital "blowout" fracture: a systematic review and meta-analysis. Otolaryngol Head Neck Surg 2016;155 (03):387-390

30 Baumann A, Ewers R. Use of the preseptal transconjunctival approach in orbit reconstruction surgery. J Oral Maxillofac Surg 2001;59(03):287-291, discussion 291-292

31 Giraddi GB, Syed MK. Preseptal transconjunctival vs. subciliary approach in treatment of infraorbital rim and floor fractures. Ann Maxillofac Surg 2012;2(02):136-140

32 Ridgway EB, Chen C, Lee BT. Acquired entropion associated with the transconjunctival incision for facial fracture management. J Craniofac Surg 2009;20(05):1412-1415

33 Zingg M, Chowdhury K, Lädrach K, Vuillemin T, Sutter F, Raveh J. Treatment of 813 zygoma-lateral orbital complex fractures. New aspects. Arch Otolaryngol Head Neck Surg 1991;117(06): 611-620, discussion 621-622

34 Graham SM, Thomas RD, Carter KD, Nerad JA. The transcaruncular approach to the medial orbital wall. Laryngoscope $2002 ; 112(06)$ : 986-989

35 Stefko ST. Fractures of the orbit. In: Myers E, Carrau RL. Operative Otolaryngology: Head and Neck Surgery. 2nd ed. Philadelphia, PA: Saunders/Elsevier; 2008

36 Borad V, Lacey MS, Hamlar DD, Dresner HS, Yadava GK, Schubert W. Intraoperative imaging changes management in orbital fracture repair. J Oral Maxillofac Surg 2017;75(09):1932-1940

37 Zavattero E, Ramieri G, Roccia F, Gerbino G. Comparison of the outcomes of complex orbital fracture repair with and without a surgical navigation system: a prospective cohort study with historical controls. Plast Reconstr Surg 2017;139(04):957-965

38 Choi M, Flores RL. Medial orbital wall fractures and the transcaruncular approach. J Craniofac Surg 2012;23(03):696-701

39 Sood A, Kogan S, Granick MS. Isolated medial orbital wall blowout fracture. Eplasty 2016;16:ic27

40 Grob S, Yonkers M, Tao J. Orbital fracture repair. Semin Plast Surg 2017;31(01):31-39

41 Rountree KM, Blase JJ. Isolated orbital roof blow-in fracture. Trauma Case Rep 2017;12:16-18

42 Righi S, Boffano P, Guglielmi V, Rossi P, Martorina M. Diagnosis and imaging of orbital roof fractures: a review of the current literature. Oral Maxillofac Surg 2015;19(01):1-4

43 Karabekir HS, Gocmen-Mas N, Emel E, et al. Ocular and periocular injuries associated with an isolated orbital fracture depending on a blunt cranial trauma: anatomical and surgical aspects. J Craniomaxillofac Surg 2012;40(07):e189-e193

44 Lin DT, Lin AC. Surgical treatment of traumatic injuries of the cranial base. Otolaryngol Clin North Am 2013;46(05):749-757

45 Apkarian AO, Hervey-Jumper SL, Trobe JD. Cerebrospinal fluid leak presenting as oculorrhea after blunt orbitocranial trauma. J Neuroophthalmol 2014;34(03):271-273

46 Borumandi F. Traumatic orbital CSF leak. BMJ Case Rep 2013

47 Pease M, Marquez Y, Tuchman A, Markarian A, Zada G. Diagnosis and surgical management of traumatic cerebrospinal fluid oculorrhea: case report and systematic review of the literature. J Neurol Surg Rep 2013;74(01):57-66

48 Gunarajah DR, Samman N. Biomaterials for repair of orbital floor blowout fractures: a systematic review. J Oral Maxillofac Surg 2013;71(03):550-570

49 Lee HB, Nunery WR. Orbital adherence syndrome secondary to titanium implant material. Ophthal Plast Reconstr Surg 2009;25 (01):33-36

50 Lee GH, Ho SY. Orbital adherence syndrome following the use of titanium precontoured orbital mesh for the reconstruction of posttraumatic orbital floor defects. Craniomaxillofac Trauma Reconstr 2017;10(01):77-83

51 Nunery WR, Tao JP, Johl S. Nylon foil "wraparound" repair of combined orbital floor and medial wall fractures. Ophthal Plast Reconstr Surg 2008;24(04):271-275

52 Groessner-Schreiber B, Neubert A, Müller WD, Hopp M, Griepentrog $M$, Lange KP. Fibroblast growth on surface-modified dental implants: an in vitro study. J Biomed Mater Res A 2003;64(04):591-599

53 Busuttil SJ, Drumm C, Plow EF. In vivo comparison of the inflammatory response induced by different vascular biomaterials. Vascular 2005;13(04):230-235

54 Katou F, Ohtani H, Nagura H, Motegi K. Procollagen-positive fibroblasts predominantly express fibrogenic growth factors and their receptors in human encapsulation process against foreign body. J Pathol 1998;186(02):201-208

55 Alkhalil M, Joshi Otero J. Orbital reconstruction with a partially absorbable mesh (monofilament polypropylene fibre and monofilament poliglecaprone-25): our experience with 34 patients. Saudi J Ophthalmol 2016;30(03):169-174

56 Kellman RM, Marentette LJ. Atlas of Craniomaxillofacial Fixation. New York, NY: Raven Press; 1995

57 Rosenberger E, Kriet JD, Humphrey C. Management of nasoethmoid fractures. Curr Opin Otolaryngol Head Neck Surg 2013;21 (04):410-416

58 Pawar SS, Rhee JS. Frontal sinus and naso-orbital-ethmoid fractures. JAMA Facial Plast Surg 2014;16(04):284-289

59 Wei JJ, Tang ZL, Liu L, Liao XJ, Yu YB, Jing W. The management of naso-orbital-ethmoid (NOE) fractures. Chin J Traumatol 2015;18 (05):296-301

60 Cultrara A, Turk JB, Har-El G. Midfacial degloving approach for repair of naso-orbital-ethmoid and midfacial fractures. Arch Facial Plast Surg 2004;6(02):133-135

61 Pham AM, Strong EB. Endoscopic management of facial fractures. Curr Opin Otolaryngol Head Neck Surg 2006;14(04):234-241

62 Markowitz BL, Manson PN, Sargent L, et al. Management of the medial canthal tendon in nasoethmoid orbital fractures: the importance of the central fragment in classification and treatment. Plast Reconstr Surg 1991;87(05):843-853

63 Papadopoulos H, Salib NK. Management of naso-orbital-ethmoidal fractures. Oral Maxillofac Surg Clin North Am 2009;21(02): 221-225, vi

64 Sargent LA. Nasoethmoid orbital fractures: diagnosis and treatment. Plast Reconstr Surg 2007;120(07, Suppl 2):16S-31S

65 Vora NM, Fedok FG. Management of the central nasal support complex in naso-orbital ethmoid fractures. Facial Plast Surg 2000; 16(02):181-191

66 Engelstad ME, Bastodkar P, Markiewicz MR. Medial canthopexy using transcaruncular barb and miniplate: technique and 
cadaver study. Int J Oral Maxillofac Surg 2012;41(10): 1176-1185

67 Ducic Y. Medial canthal ligament reattachment in skull base surgery and trauma. Laryngoscope 2001;111(4, Pt 1):734-737

68 Becelli R, Renzi G, Mannino G, Cerulli G, Iannetti G. Posttraumatic obstruction of lacrimal pathways: a retrospective analysis of 58 consecutive naso-orbitoethmoid fractures. J Craniofac Surg 2004; 15(01):29-33

69 Ali MJ, Gupta H, Honavar SG, Naik MN. Acquired nasolacrimal duct obstructions secondary to naso-orbito-ethmoidal fractures: patterns and outcomes. Ophthal Plast Reconstr Surg 2012;28(04): 242-245 